\title{
Numerical Simulation of Fertilizers Movement in Sand and Controlling Transport Process via Vertical Barriers
}

\author{
Mohamed Galal A. Eltarabily and Abdelazim M. Negm
}

\begin{abstract}
Intensive application of inorganic compounds for agriculture activities leads to increased percolation into the subsurface and can end up in the groundwater. Nitrate is considered a moderate solute in soils and could move quickly through the soil especially on sandy or permeable soils profile leading to groundwater pollution. This paper presents an application of numerical models in order to investigate the migration process of nitrates through sand. Two software products, SEEP/W and CTRAN/W, are used to analyze the contaminant transport. These models can be used to optimize agricultural practice aiming to minimize the impact on the environment. Nitrate sorption in the sand is influenced by environmental conditions which contributing to the migration process of nitrate in soil. The behavior of nitrate transport through sand is tested when vertical wall of sheet pile is used as a barrier. The involved parameters are the penetration depth of protection wall, location of wall from the pollution source, and the head deference of the water level. The results show that the physical properties of soil have significant effect on the movement of the contaminant. Also, the results indicate that the change in head difference has insignificant effect on the contaminant migration process. Finally, the best location and depth of the vertical barrier are determined to minimize the proportion of the reached contaminant to attain the maximum possible protection of the drain's water.
\end{abstract}

Index Terms-Advection-dispersion, contaminant migration, nitrate concentration, sheet pile, soil absorption, soil protection.

\section{INTRODUCTION}

Agricultural wastewater is mainly consists of Nutrients (nitrogen and phosphorus) that is typically applied to farmland as commercial fertilizer (inorganic nitrogen fertilizers) and animal manure. Nitrates are mainly produced for use as fertilizers in agriculture because of their high solubility and biodegradability [1]. The main nitrates are ammonium, sodium, potassium, and calcium salts.

The groundwater pollution by nitrate is an international problem (Roberts and Marsh, 1987; Meybech M., D. Chapman and P. Helman, 1989; Spalding and Exner, 1993; Zhang, W.I., Z.X. Tian, N. Zhang and X.Q. Li, 1996; Lerner, 1999; Wakida and Lerner, 2002) [2]-[7]. Nitrate $\left(\mathrm{NO}_{3}^{-}\right)$is a leaching pollutant from fertilizer application in soil and groundwater [8]. The pollution of groundwater by nitrate

Manuscript received August 9, 2014; revised October 31, 2014. This work was supported in part by the Egyptian Ministry of Higher Education (MoHE) and Egypt-Japan University of Science and Technology (E-JUST), JICA and JSPS

The authors are with the Environmental Engineering Department, School of Energy and Environmental Engineering, Egypt- Japan University of Science and Technology (E -JUST), New Borg Al-Arab City, 21934, Alexandria, Egypt (e-mail: mohamed.eltarabily@ejust.edu.eg, amnegm@zu.edu.eg).
$\left(\mathrm{NO}_{3}{ }^{-}\right)$has been a frequent matter in aquifers in the world (UNEPE, 1991). The highly use of fertilizers makes the problem of agricultural pollution worse. It can provide valuable plant nutrients. However, if not managed correctly, excess $\mathrm{N}$ and $\mathrm{P}$ can have negative environmental consequences.

Due to environmental interest of water and soil pollution, the given attention now is focused on studying the water and nitrates movement through the soil. The infiltration of $\mathrm{N}^{-}$ contains pollutants from surface water. The transport process of nitrate contaminants through soil and groundwater occurs via a series of complex chemical and hydraulic phenomena (Chao and Pei-Fang, 2008) [1], [9]. The high doses of nitrogenous/phosphorous fertilizer applied to the soil immediately followed by massive irrigation water causes some nitrogen losses and risk of nitrates penetration to subsoil, Thus once ecosystems are contaminated by these elements, they become potential threat for many years [10], [11]. The amount of nitrate leakage is affected by nitrate formation in the soil, water movement and soil structure (White and Sharpley, 1996 and Abdel-Nasser, 2001). In general any factor influencing soil moisture (such as rainfall, irrigation, evaporation and transpiration) will impact nitrate movement [12], [13].

The two-dimensional physical model developed in the laboratory allows conducting easily various combinations concerning the soil, the water head and the boundary conditions in order to simulate field situations. However the image analysis technique using fluorescent dye tracer is a useful method in determining transient phenomena for water and contaminant migration, especially in case of rapid changes in water content and contaminant concentration [9].

Nitrate $\left(\mathrm{NO}_{3}{ }^{-}\right)$is the primary form of $\mathrm{N}$ leached into groundwater, is totally soluble at the concentrations found in soil, and moves freely through most soils. As described by Jury and Nielson (1989), movement of the $\mathrm{NO}_{3}{ }^{-}$ion through soil is governed by convection, or mass flow, with the moving soil solution and by diffusion within the soil solution. The widespread appearance of $\mathrm{NO}_{3}{ }^{-}$in ground water is a consequence of its high solubility, mobility, and easy displacement by water.

Nitrate leaching from many types of soils or under different fertilizer rates can be calculated by using numerical models which simulate $\mathrm{NO}_{3}{ }^{-}$distribution under laboratory and field conditions (Sharmasarkar, F.C. and R. Zhang, 2000; Abdel-Nasser, 2001; Duwing, C., T. Becquer, L. Charlet and B.E. Clothier, 2003) [14], [15]. These models have a varied degree of abstraction concerning the simulation of complex physical and biochemical soil processes and for that reason it is not easy to choose a suitable model to estimate the impact of agriculture on groundwater pollution. The choice of using 
two software, CTRAN/W are used in conjunction with SEEP/W, makes it possible to analyze problems varying from simple particle tracking in response to the movement of water, to complex processes involving diffusion, dispersion, adsorption, radioactive decay and density dependencies.

Anderson, and Mesa (2006), investigated the effect of vertical barrier walls or /and well on the hydraulic control of contaminated groundwater. They used impermeable circular arc wall with finite length where the centre of curvature is downstream the arc. The domain is infinite and homogenous and the flow is steady and uniform. They found that the barrier wall created two stagnation points in the field. One of them is in up gradient side and the other one is in down gradient side. At every stagnation point, there exists a region of low discharge at interior side of curvature. This region may be used to slow the movement of contamination [16], [17].

\section{NumericAl SOLUTION OF THE PROBLEM}

There are many numerical solution methods such as Finite Differences (FDM), Finite Elements (FEM) and Boundary Elements (BEM). The FEM is an effective numerical technique because of its numerous applied fields such as groundwater flow, multiphase flow, and mass flow through pours medium. It is flexible in simulation and introduce accurate.

\section{A. General Description of SEEP/W and CTRAN/W Models}

SEEP/W is a finite element software product for analyzing groundwater seepage and excess pore-water pressure dissipation problems within porous materials such as soil and rock. It can model, in addition to traditional steady-state saturated flow, both saturated and unsaturated flow, that makes it possible to analyze seepage as a function of time and to consider such processes as the infiltration of precipitation. CTRAN/W is a finite element software product that can be used to model the movement of contaminants through porous materials. It utilizes the SEEP/W flow velocities to compute the movement of dissolved constituents in the pore-water. All Geostudio package are free online [18].

The inclusion of unsaturated flow in groundwater modeling is important for obtaining physically realistic analysis results. In soils, the hydraulic conductivity and the water content, or water stored, changes as a function of pore-water pressure. SEEP/W models these relationships as continuous functions. Furthermore, many contaminant transport problems may be simplified by using steady-state groundwater flow. In other cases, transient groundwater flow is required. SEEP/W can be used to generate a steady state or transient groundwater flow solution for CTRAN/W [19] (Table I).

\section{B. Analysis Types}

\section{1) Particle tracking analysis, PTA}

The PTA gives an idea of the contaminant travel distances and travel times. Whereas particle tracking is a quick way of presenting the contaminated region, a complete advection dispersion analysis is required to know the concentration within the contaminated region.

\section{2) Advection-dispersion analysis}

Advection refers to the process by which solutes are transported by the bulk motion of flowing groundwater. Dispersion refers to the phenomenon of contaminant spreading from the path that it would be expected to follow according to the advective hydraulics of the flow system. Virtually all contaminant transport analyses require computation of advection and dispersion.

The differential equation which describes advective-dispersive contaminant transport is known as the advection-dispersion equation. The derivation of the equation should be carried by applying the principle of mass balance to an element of porous medium and considers the processes of advection and dispersion. Additional terms which include the effect of adsorption and decay have also been derived. The following is the one-dimensional form of the advection-dispersion equation (Geo-Slope User's Guide).

$$
\theta D \frac{\partial^{2} C}{\partial x^{2}}-U \frac{\partial C}{\partial x}-\lambda \theta C-\lambda S \rho_{d}=\left(\theta+\rho_{d} \frac{\partial S}{\partial C}\right) \frac{\partial C}{\partial t}
$$

where:

$C=$ concentration.

$\theta=$ volumetric water content.

$D=$ hydrodynamic dispersion coefficient.

$U=$ Darcy velocity.

$S=$ adsorption.

$\rho_{d}=$ bulk (dry) mass density of the porous medium.

$t=$ time.

$x=$ distance in the $\mathrm{x}$ direction.

The first term in the equation represents transport by dispersion, the second represents transport by advection, the third represents decayed mass loss in the fluid phase, and the fourth represents decayed mass loss in the solid phase. The term on the right side of the equation represents storage of mass in the fluid phase and in the solid phase due to a change in concentration. CTRAN/W implements the two dimensional form of the advection-dispersion equation shown above [20].

The Objective of the present study is the movement of nitrates through the sandy soil and the use of sheet pile as a vertical barrier to control contaminant transport in the soil. Process of controlling contaminant transport is the process of containing or redirecting of contaminants to a cretin direction or position for a period of time. The flow is considered to be steady-state, two dimensional in a homogeneous isotropic porous media. An impermeable vertical sheet pile is embedded to depth $(D)$ in the domain with the change of its location.

\section{MODEL IMPLEMENTATION}

TABLE I: PARAMETERS OF HYDRAULIC FUNCTIONS FOR SAND USED IN THE SEEP/W SIMULATION

\begin{tabular}{ll}
\hline \hline Parameter & Value \\
\hline Saturated water content $\left(\theta_{s}\right)$ (Fig. 1) & $\left(0.65 \mathrm{~m}^{3} / \mathrm{m}^{3}\right)$ \\
\hline Residual water content $\left(\theta_{r}\right)$ & $\left(0.30 \mathrm{~m}^{3} / \mathrm{m}^{3}\right)$ \\
\hline Saturated hydraulic conductivity $\left(K_{s}\right)($ Fig. 2$)$ & $\left(1.01 \times 10^{-4} \mathrm{~m} / \mathrm{s}\right)$ \\
\hline \hline
\end{tabular}




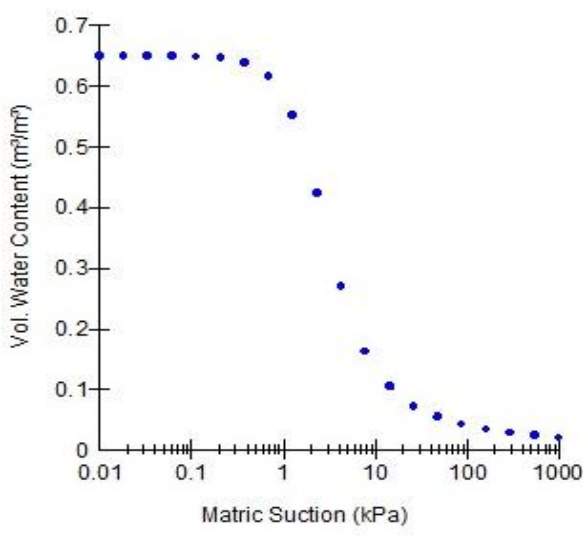

Fig. 1. The saturated water content function.

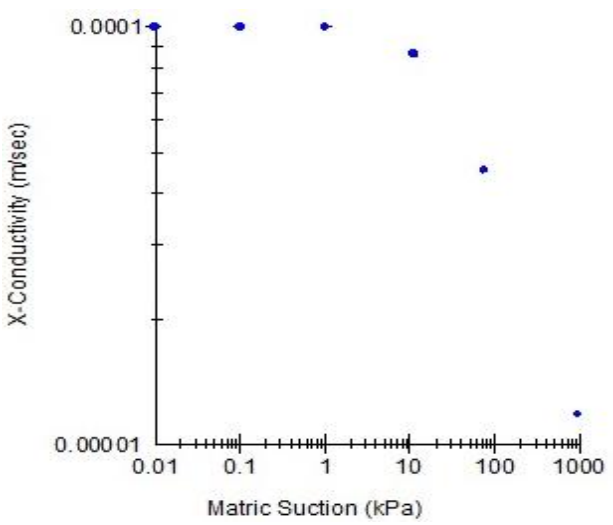

Fig. 2. The saturated hydraulic conductivity.

TABLE II: THE ADSORPTION CAPACITY AND RETAINED PERCENTAGES AT DiFFERENT INITIAL CONDITIONS FOR SANDY SOIL AT $15^{\circ} \mathrm{C}, 25^{\circ} \mathrm{C}$, AND $35^{\circ} \mathrm{C}$ [26] (FIG. 3)

\begin{tabular}{lllllll}
\hline \hline \multirow{2}{*}{$\begin{array}{c}\mathrm{C}_{0} \\
(\mathrm{mg} / \mathrm{L})\end{array}$} & \multicolumn{2}{c}{$15^{\circ} \mathrm{C}$} & \multicolumn{2}{c}{$25{ }^{\circ} \mathrm{C}$} & \multicolumn{2}{c}{$35{ }^{\circ} \mathrm{C}$} \\
\cline { 2 - 7 } & $\begin{array}{l}\text { Qeq. } \\
(\mathrm{mg} / \mathrm{g})\end{array}$ & Ads. \% & $\begin{array}{l}\text { Qeq. } \\
(\mathrm{mg} / \mathrm{g})\end{array}$ & Ads. \% & $\begin{array}{l}\text { Qeq. } \\
(\mathrm{mg} / \mathrm{g})\end{array}$ & Ads. \% \\
\hline 25 & 0.038 & 15.20 & 0.040 & 15.98 & 0.027 & 10.60 \\
\hline 50 & 0.091 & 18.20 & 0.087 & 17.39 & 0.060 & 12.10 \\
\hline 100 & 0.199 & 19.94 & 0.186 & 18.60 & 0.131 & 13.10 \\
\hline 200 & 0.425 & 21.25 & 0.412 & 20.60 & 0.300 & 15.01 \\
\hline 500 & 1.249 & 24.98 & 1.132 & 22.60 & .851 & 17.01 \\
\hline \hline
\end{tabular}

\section{A. Steady-State Diffusion in Free Solution}

Diffusion of a chemical or chemical species in solution typically is assumed to occur in response to a concentration gradient in accordance with Fick's first law which, for one dimension, may be written as:

$$
J=-D_{0} \frac{\partial C}{\partial x}
$$

where $J=$ the mass flux, $C=$ the concentration of the solute in the liquid phase, $x=$ the direction of transport, and $D_{0}=$ the "free-solution" diffusion coefficient. However, several investigators [e.g., Robinson and Stokes (1959), Quigley, R. M., Yanful, E. K., and Fernandez, F. (1987), Daniel and Shackelford (1987), and Shackelford (1988, 1989)] have noted that there is a more fundamental basis for diffusive transport than the empirical Fick's first law [21]-[24] (Fig. 4).

The self-diffusion coefficient for representative anion $\left(\mathrm{NO}_{3}{ }^{-}\right)$at infinite dilution in water at $25^{\circ} \mathrm{C}$ is $D_{0}=19 \times 10^{-10}$ $\left(\mathrm{m}^{2} / \mathrm{s}\right)$. This value of $D_{0}$ should be considered to be the maximum value attainable under ideal conditions (i.e., molecular scale, infinite dilution) [25].

\section{B. Effect of Initial Nitrate Concentration on Adsorption}

Since the initial nitrate concentration in water provides an important driving force to overcome all mass transfer limitations of nitrate between aqueous and solid phases, a higher initial nitrate concentration will enhance the adsorption process. The effect of initial nitrate concentration on the adsorption of nitrate on sandy soil was investigated in concentration ranges between $(25 \mathrm{mg} / \mathrm{L})$ and $(500 \mathrm{mg} / \mathrm{L})$ at $15^{\circ} \mathrm{C}, 25^{\circ} \mathrm{C}$, and $35^{\circ} \mathrm{C}[26]$.

In Table II, it is observed that the amount of adsorbed nitrate at equilibrium increased with increasing initial nitrate concentration but decreased with temperature. Also it indicates that the percentages of nitrate retained by all soil samples increased as the initial nitrate concentration increased whereas decreasing with an increase in temperature.

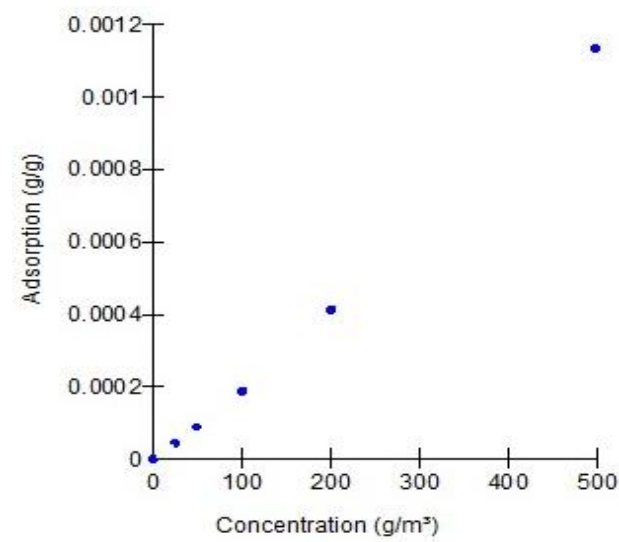

Fig. 3. Adsorption function for sand at $25^{\circ} \mathrm{C}$.

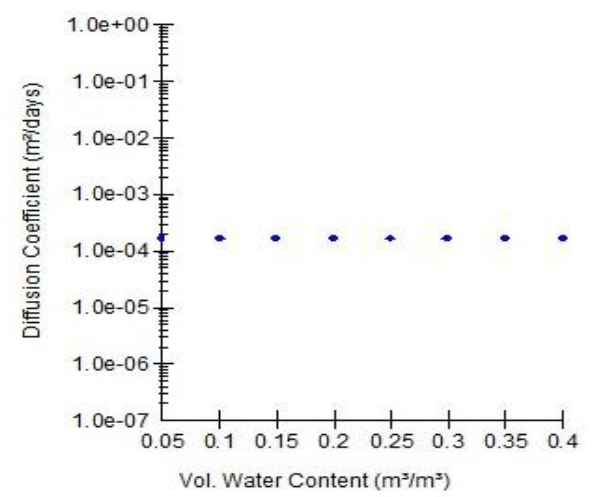

Fig. 4. Diffusion coefficient for nitrate $=\left(1.6416 \times 10^{-4} \mathrm{~m} /\right.$ day $)$.

\section{The Boundary Conditions of the Model}

The model is two dimension, the hydraulic conductivities $K_{x} / K_{y}=1$, the porosity $(n)=50 \%$, the longitudinal dispersivity / transverse dispersivity $=2$ and the time step sequence consists of ten steps. Time starts in zero days and ends in 100 days.

\section{RESULTS AND DISCUSSION}

In order to model the contaminant migration in unsaturated soil, SEEP/W was firstly run. The flow is proportional to the hydraulic gradient and the hydraulic conductivity (coefficient of permeability). After set the geometry (a $35 \mathrm{~m}$ in length $\times$ $15 \mathrm{~m}$ in depth soil) and the grid (mesh $0.5 \times 0.5 \mathrm{~m}$ ) as shown in Fig. 5, input data are required: coefficient of permeability, 
water content (as reported in Table I). Boundary conditions were specified as total head $(H)$ (Fig. 6). The SEEP/W contour function allows one to graphically view the results by displaying velocity vectors that represent the flow direction. A vector is drawn in each element, with the end point of the vector at the centre point of the element. The vector represents the average velocity within the element. The seepage flow velocities computed from SEEP/W are then used by CTRAN/W for the contaminant transport analysis.

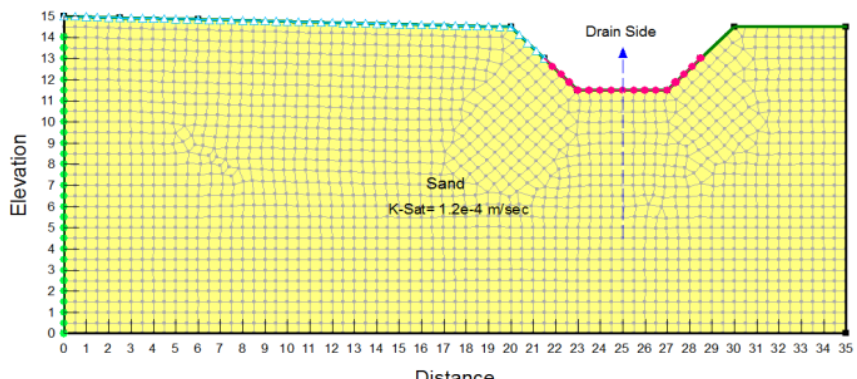

Fig. 5. The mesh of the domain showing the boundary conditions for SEEP/W analysis.

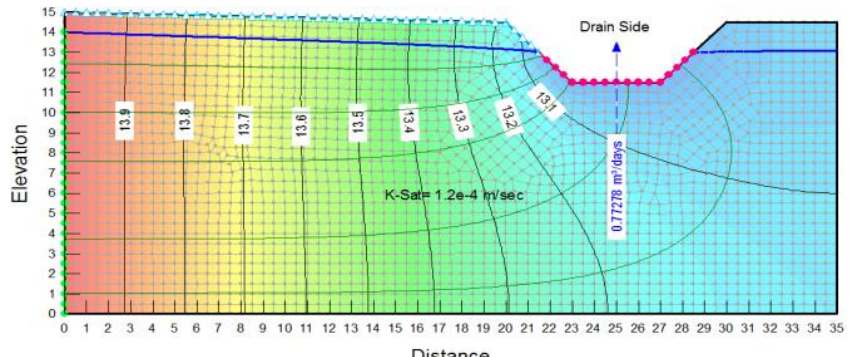

Fig. 6. Total head distribution and flux section at the drain side.

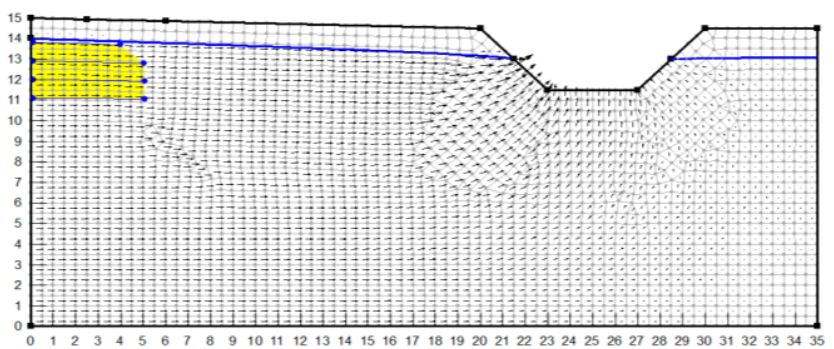

Fig. 7a. Particle tracking analysis after 10 days.

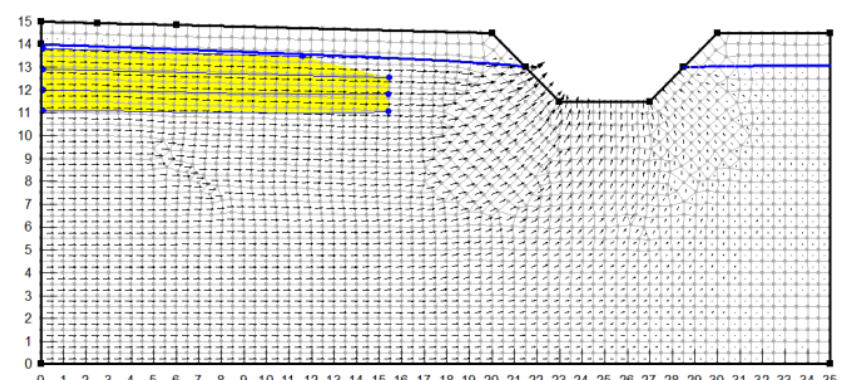

Fig. 7b. Particle tracking analysis after 30 days.

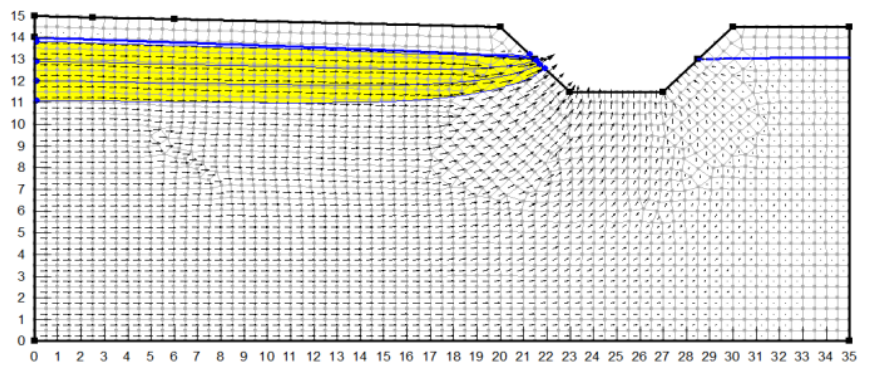

Fig. 7c. Particle tracking analysis after 60 days.
In particle tracking analysis, the dissolved solutes are represented by particles. Fig. $7(\mathrm{a}-\mathrm{c})$ is an example of a particle tracking analysis. For each time step, the particles are moved in space proportionally to the water flow velocity and the time step size. The particle flow paths provide a graphical representation of the contaminant plume movement caused by purely advective transport; the effects of dispersion, adsorption, decay and density are not considered. It is possible to view the travel time, location, distance travelled and average speed of a theoretical particle at any point along its flow path.

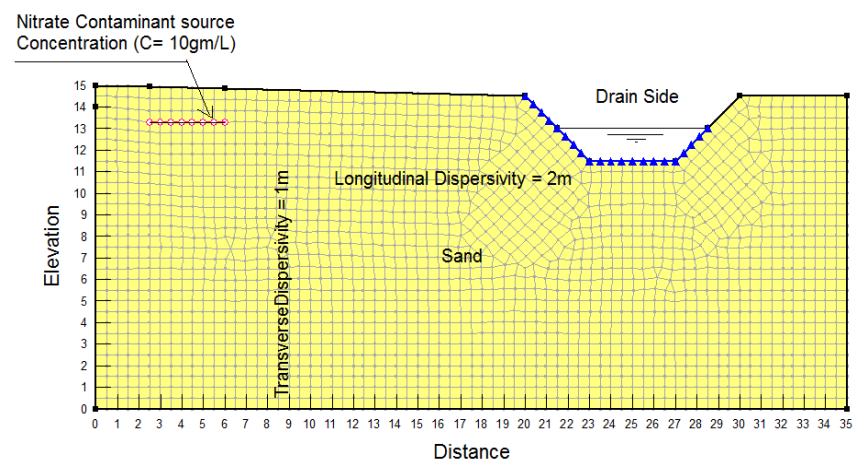

Fig. 8. Geometry and boundary conditions for CTRAN/W model analysis.

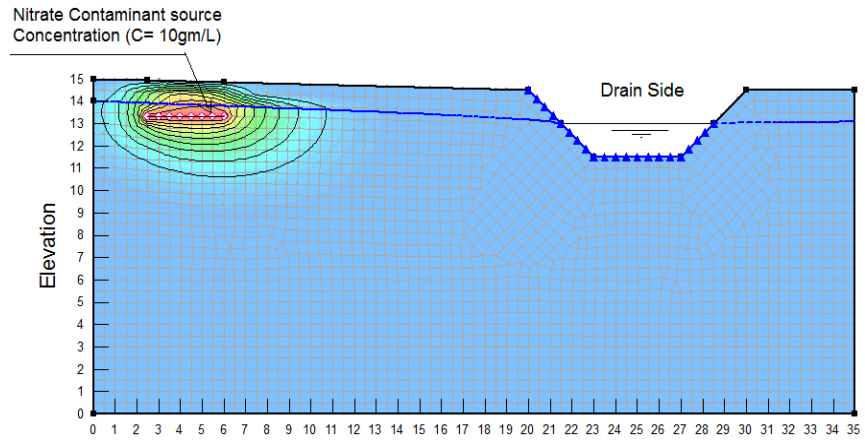

Fig. 9a. Advection-dispersion analysis after 10 days.

Nitrate Contaminant source

Concentration $(C=10 \mathrm{gm} / \mathrm{L})$

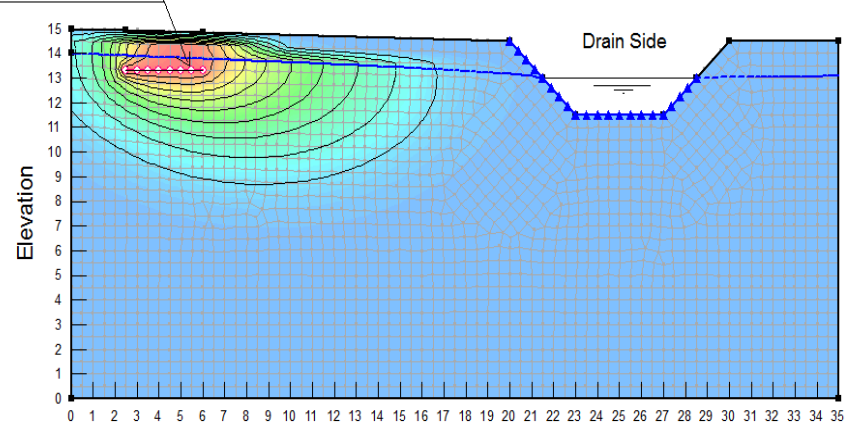

Fig. 9b. Advection-dispersion analysis after 30 days.

Nitrate Contaminant source

Concentration $(C=10 \mathrm{gm} / \mathrm{L})$

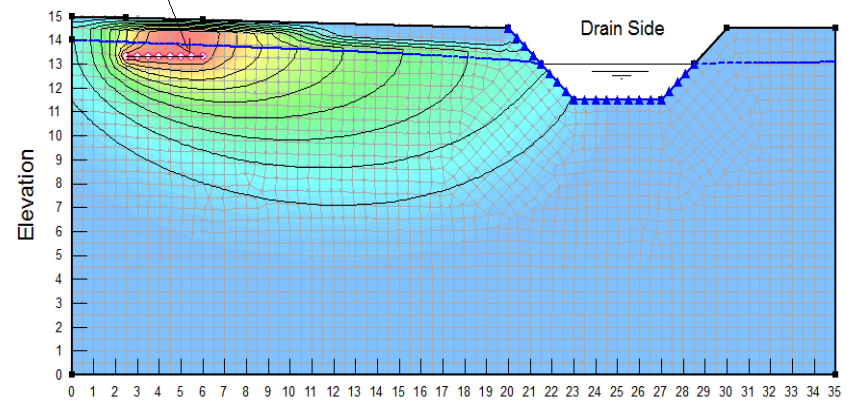

Fig. 9c. Advection-dispersion analysis after 60 days. 


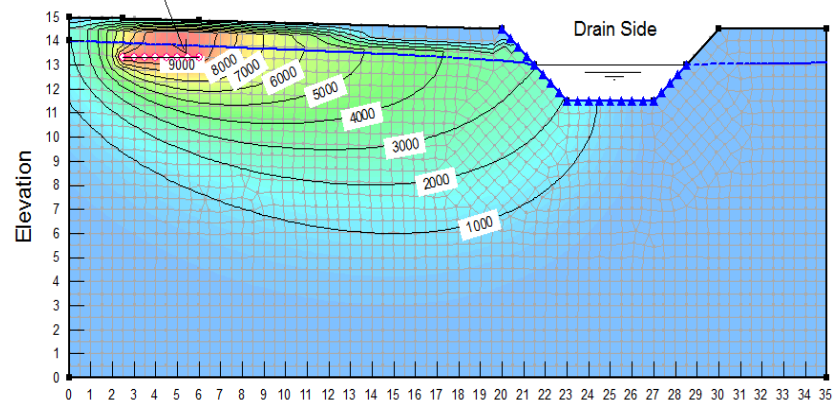

Fig. 9d. Advection-dispersion analysis after 100 days.

For particle tracking analysis, it is observed that the average velocity for the four points defined in the region approximately equal $(0.48 \mathrm{~m} /$ day $)$ until ten days, $(0.5 \mathrm{~m} /$ day $)$ until thirty days and $(0.56 \mathrm{~m} /$ day $)$ until sixty days.

In the advection-dispersion analysis, adsorption of contaminant on the soil particles is linearly related to concentration. This is the concept of chemical partitioning between the fluid and solid phases, quantified by a chemical partitioning coefficient. CTRAN/W allows a more general relation to be used to specify the chemical partitioning by allowing the adsorption to be specified as a function of concentration. In effect, this means that the chemical partitioning coefficient, (which is the slope of the adsorption/concentration function), can be specified as a function of concentration (Fig. 8). Fig. 9a to Fig. 9d are graphical representations of advection-dispersion analysis of a solution of nitrate; starting concentration $(10 \mathrm{gm} / \mathrm{l})=$ $\left(10000 \mathrm{gm} / \mathrm{m}^{3}\right)$.

In case of using sheet pile, the water flux at the drain side equals $\left(0.62258 \mathrm{~m}^{3} /\right.$ days $)$ this value is less than the flux without using the sheet pile, this reflects that the water flow velocity has decreased (Fig. 10-Fig. 15).

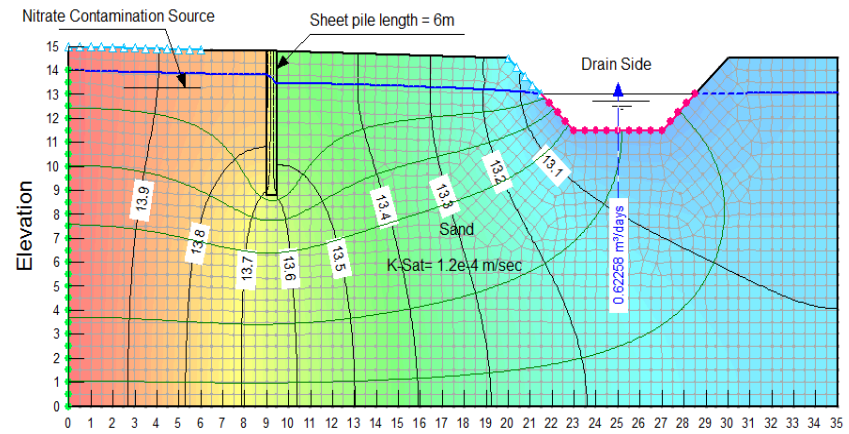

Fig. 10. Total head distribution and flux section at the drain side in case of using sheet pile at the contamination side.

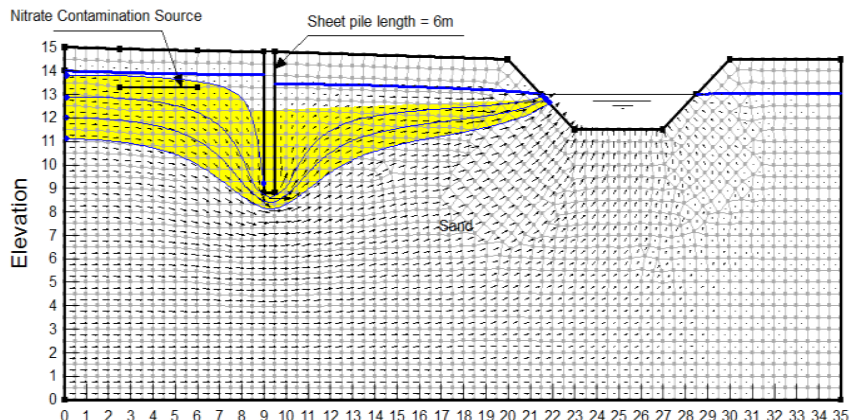

Fig. 11. Particle tracking analysis after 60 days with sheet Pile $(6 \mathrm{~m})$ in length at the contamination side.
For particle tracking analysis in case of using the sheet pile as a vertical barrier, it is observed that the average velocity for the four points defined in the region approximately equal $(0.34 \mathrm{~m} /$ day $)$ until ten days, $(0.4 \mathrm{~m} /$ day $)$ until thirty days and $(0.46 \mathrm{~m} /$ day $)$ until sixty days.

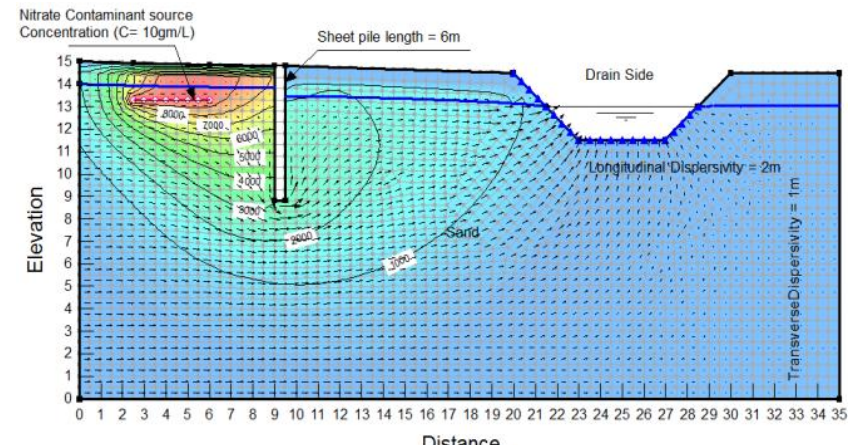

Fig. 12. Advection-dispersion analysis after 100 days using sheet pile $(6.0 \mathrm{~m})$ in length at the contamination side.

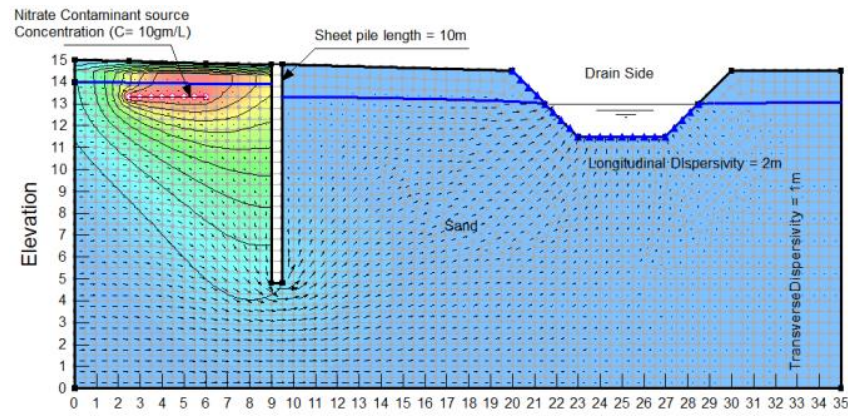

Fig. 13. Advection-dispersion analysis after 100 days using sheet pile (10.0 $\mathrm{m}$ ) in length at the contamination side.

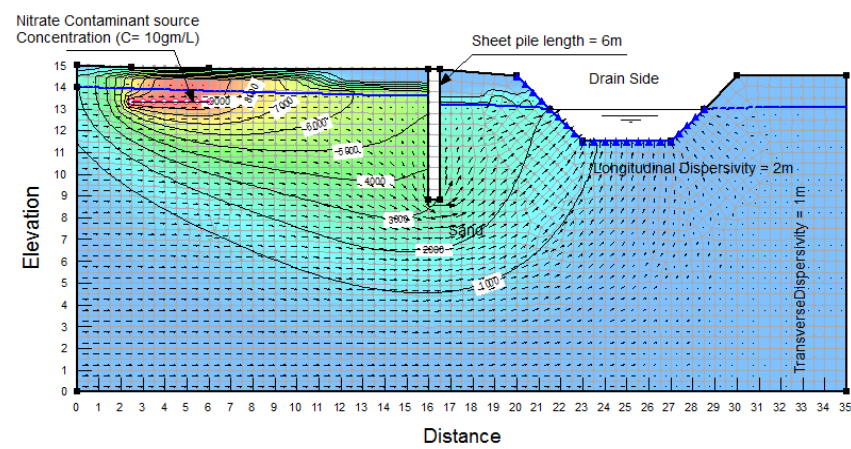

Fig. 14. Advection-dispersion analysis after 100 days using sheet pile $(6.0 \mathrm{~m})$ in length at the drain side.

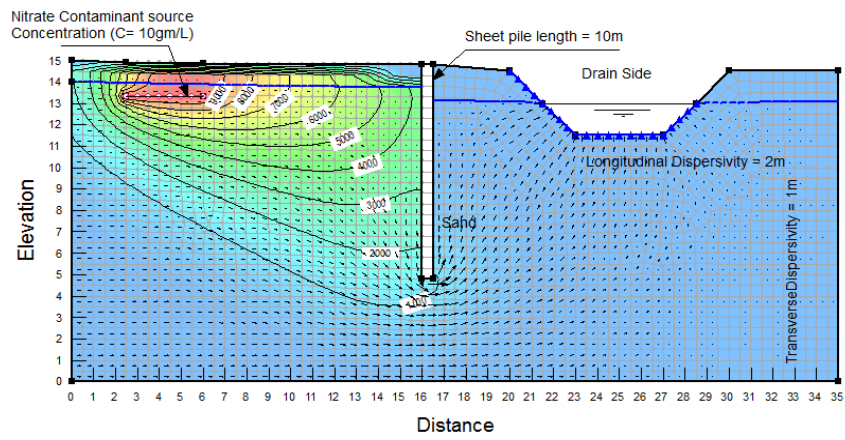

Fig. 15. Advection-dispersion analysis after 100 days using sheet pile (10.0 $\mathrm{m})$ in length at the drain side.

Results of nitrate concentration through soil profile at the toe point of the drain's slope for numerical simulation results Fig. 16(a-d) show that nitrate concentration after 100 days was $\left(1879.09 \mathrm{gm} / \mathrm{m}^{3}\right)$ without any controlling barriers, it was 
$\left(1368.94 \mathrm{gm} / \mathrm{m}^{3}\right)$ while using the sheet pile with penetration depth $6.0 \mathrm{~m}$ at the drain side, it was $\left(366.1 \mathrm{gm} / \mathrm{m}^{3}\right)$ while using the sheet pile with penetration depth $6.0 \mathrm{~m}$ at the contaminant source, it was $\left(35.61 \mathrm{gm} / \mathrm{m}^{3}\right)$ while using the sheet pile with penetration depth $10.0 \mathrm{~m}$ at the drain side, and it was $(8.72$ $\mathrm{gm} / \mathrm{m}^{3}$ ) while using the sheet pile with penetration depth $10.0 \mathrm{~m}$ at the contaminant source.

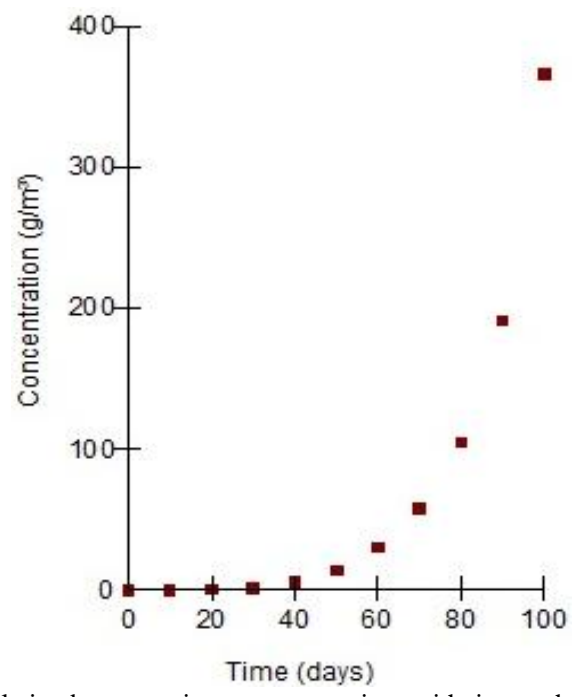

Fig. 16a. Relation between nitrate concentrations with time at the slope toe of the drain, sheet pile $(6.0 \mathrm{~m})$ at the contaminant source.

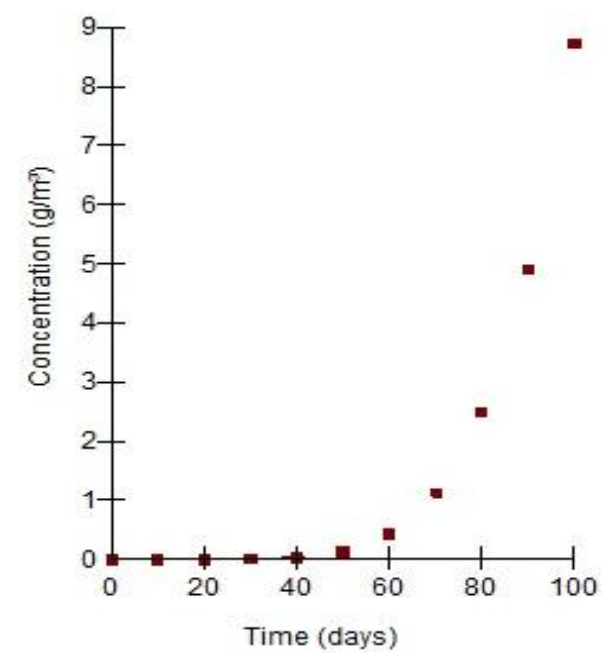

Fig. 16b. Relation between nitrate concentrations with time at the slope toe of the drain, sheet pile $(10.0 \mathrm{~m})$ at the contaminant source.

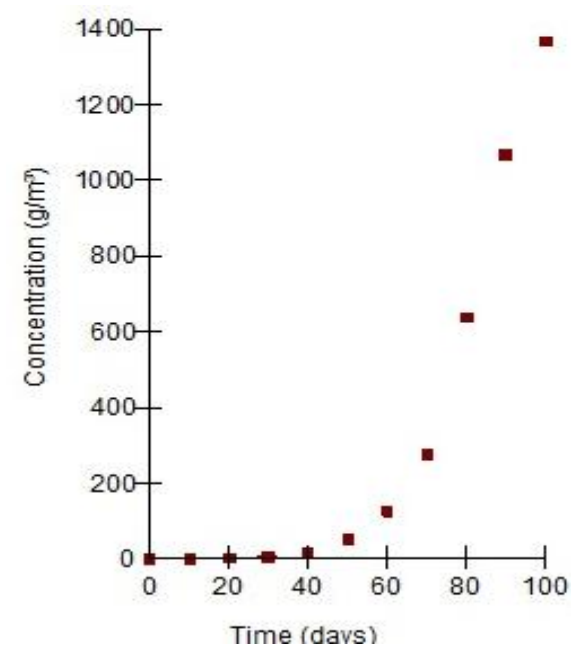

Fig. 16c. Relation between nitrate concentrations with time at the slope toe of the drain, sheet pile $(6.0 \mathrm{~m})$ at the drain side.

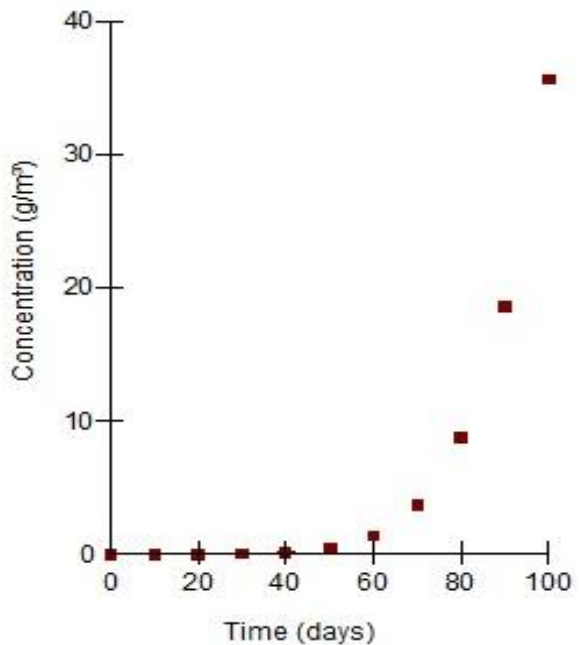

Fig.16d. Relation between nitrate concentrations with time at the slope toe of the drain, sheet pile $(10.0 \mathrm{~m})$ at the drain side.

\section{CONCLUSION}

Within the materials presented in this paper, the following conclusions are stated:

- The distance of contaminant transport significantly depends on the hydraulic conductivity of the soil and the diffusion coefficient $\left(D_{0}\right)$ of contaminant Anion or Cation.

- In case of increasing time, the existence of the contaminants is in a far distance in the soil media.

- The movement of contaminants in course soils (gravel and sand) is greater than its movement in fine soil (silt and clay).

- The average particles tracking velocity in the soil significantly depends on the water velocity and their total distance traveled depends on the time.

- The rate of advective contamination transport can be significantly reduced when the wall placed up gradient of contaminant source rather than down gradient, where it reduces the plume width.

- The total flux at drain side is decreased in case of using the sheet pile rather than the useless of the sheet pile because the velocities magnitudes have decreased.

- In case of using the sheet pile, the concentration of the contaminant does not reach the side slopes of the drain so that it does not affect the slope stability.

- The best position of the sheet pile to reduce the reached contaminants to drain side is near the leading edge of the contaminant plume (recharge). The sheet pile must penetrate the low hydraulic conductivity layer soil to achieve its purpose for controlling the transport process of the contaminant.

- Existence of sheet pile hasn't any significant effect on contamination transport when the hydraulic conductivity of the aquifer is less than $1 \times 10^{-8}(\mathrm{~m} / \mathrm{s})$ because it is considered impermeable.

- Also, the study has shown that the existence of the vertical sheet pile causes an increase in the concentration of contamination below the lower edge of sheet pile.

\section{ACKNOWLEDGMENT}

The first author would like to thank Egyptian Ministry of 
Higher Education (MoHE) for providing him the financial support ( $\mathrm{PhD}$ scholarship) for this research as well as the Egypt Japan University of Science and Technology (EJUST) and JICA for offering the facility and tools needed to conduct this work. This work was partially supported by JSPS Core-to-Core Program, B.Asia-Africa Science Platforms.

\section{REFERENCES}

[1] W. Chao and P.-F. Wang, "Migration of infiltrated $\mathrm{NH}_{4}$ and $\mathrm{NO}_{3}$ in a soil and groundwater system simulated by a soil tank," Journal of Soil Science Society of China, vol. 18, pp. 628-637, 2008.

[2] S. K. Gunatilake and Y. Iwao, "A Comparison of nitrate distribution in shallow groundwater of two agricultural areas in Sri Lanka and in Japan,” Sabaramuwa University Journal, vol. 9, no.1, pp. 81-95, 2010.

[3] G. Roberts and T. Marsh, "The effect of agricultural practices on the nitrate concentrations in the surface water domestic supply sources of western Europe," IAHS, vol. 164, pp. 365-380, 1987.

[4] M. Meybeck, D. Chapman, and P. Helman, "Global freshwater quality: A first assessment, global environment monitoring system," UNEP/WHO, 1989.

[5] R.F. Spalding and M. E. Exner, "Occurrence of nitrate in groundwater — A review,” Journal of Environmental Quality, vol. 22, pp. 392-402, 1993.

[6] W. I. Zhang, Z. X. Tian, N. Zhang, and X. Q. Li, "Nitrate pollution of groundwater in Northen China," Agricultural Ecosystem Environment, vol. 59, pp. 223-231, 1996.

[7] F. T. Wakida and D. N. Lerner, "Nitrate leaching from construction sites to groundwater in Nottingham, UK, urban area," Water Sci. Technology, vol. 45, pp. 243-248, 2002.

[8] C. Srilert, L. Chutinun, S. Wattasit, S. Sumana, and S. Chakkaphan, "Effect of soil water characteristics curves in simulation of nitrate vertical transport in Thai agricultural soil," Sustainable Environmental Resources, vol. 21, no. 3, pp. 187-193, 2011.

[9] M. Jassam, A. Dufour, N. Jozja et al., "Transport of nitrate through saturated-unsaturated soils considering nonhomogeneous soil profile," International Journal of Geology, Earth \& Environmental Sciences, vol. 4, no. 1, pp. 8-22, 2014.

[10] S. Padaki, Shivasharanappa, and K. Srinivas, "Adsorption studies of nitrate by geo-physical environment (lateritic soil) of the study area bidar urban \& its industrial area, Karnataka State, India," International Letters of Chemistry, Physics and Astronomy, vol. 6, pp. 66-76, 2013.

[11] N. Katarina and N. Dusan, "The influence of irrigation on nitrates movement in soil and risk of subsoil contamination," Soil \& Water Resources, vol. 4, no. 2, pp. 131-136, 2009.

[12] R. E. White and A. N. Sharpely, "The fate of nonmetal contaminants in the soil environment," in Contaminants and the Soil Environment in the Australasia-Pacific Region, R. Naidu et al., Ed. Kluwer Acedemic Publishers, Dordrecht, the Netherlands, 1996, pp. 29-68.

[13] G. Abdel-Naseer, "Laboratory study of groundwater pollution with nitrate," Journal of Agricultural Science Mansoura University, vol. 26 , pp. 6591-6606, 2001.

[14] C. Duwing, T. Becquer, L. Charlet, and B. E. Clothier, "Estimation of nitrate retention in ferralsol by a transient-flow method," European Journal of Soil Science, vol. 54, pp. 505-515, 2003.

[15] F. C. Sharmasarkar and R. Zhang, "Modeling nitrate movement in sugar beet soils under flood and drip irrigation," ICID Journal, vol. 49, pp. 43-54, 2000.

[16] I. Erik and M. Elizabeth, "The effects of vertical barrier walls on the hydraulic control of contaminated groundwater," Advances in Water Resources, vol. 29, pp. 89-98, 2006.

[17] E. Mesa, "Vertical barriers for the hydraulic control of groundwater," Ph.D. Thesis in Civil and Environmental Engineering, College of Engineering and information Technology, University of South Carolina, p. 146, 2006.

[18] GEO-SLOPE User's Guide, CTRAN/W and SEEP/W. [Online]. Available: http://www.geoslope.com
[19] G. Siracusa, A. D. La Rosa, and L. Musumeci, "Modeling of contaminant migration in unsaturated soils," WIT Transactions on Ecology and the Environment, vol. 102, 2007.

[20] J. C. Van Dam and R. A. Feddes, "Numerical simulation of infiltration, evaporation and shallow groundwater levels with Richards's equation," Journal of Hydraulic, vol. 233, pp. 72-85, 2000.

[21] R. A. Robinson and R. H. Stokes, Electrolyte Solutions, $2^{\text {nd }}$ ed. Butterworth's Scientific Publications, London, England, 1959.

[22] R. M. Quigley, E. K. Yanful, and F. Fernandez, "Ion Transfer by Diffusion through Clayey Barriers," Geotechnical Practice for Waste Disposal, ASCE, New York, vol. 13, pp. 137-158, 1987.

[23] D. E. Daniel and C. D. Shackelford, "Disposal barriers that release contaminants only by molecular diffusion," Nucl. Chem. Waste Management, vol. 8, pp. 299-305, 1988.

[24] C. D. Shackelford, "Diffusion of inorganic chemical wastes in compacted clay," Ph.D. dissertation, University of Texas, Austin, Tex., 1988.

[25] D. C. Shackelford and E. D. Daniel, "Diffusion in saturated soil. I: Background," Journal of Geotechnical Engineering, vol. 117, no. 3, March 1991.

[26] A. Cevdet and O. Tuba, "Adsorption dynamic and equilibrium studies of nitrate onto various soils," Fresenius Environmental Bulletin, vol. 19 , no. $10,2010$.

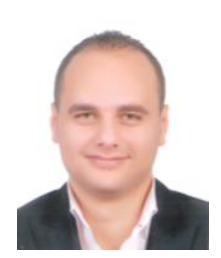

Mohamed Galal Awad El-Tarabily was born in Port Said, Egypt on November 29, 1987. He graduated in May 2009 from Suez Canal University, Port Said, Egypt and was awarded the B.Sc. degree in civil engineering and was awarded the master degree of science in civil engineering (irrigation and water resources).

He was employed as a tutor in the Civil Engineering Department, Faculty of Engineering, Port Said University, Egypt from September 1, 2010 to July 13, 2012; employed as an assistant lecturer in the Civil Engineering Department, Faculty of Engineering, Port Said University, Egypt from July 14, 2012 to February 22, 2014. From February 23, 2014, he is a Ph.D student in Egypt-Japanese University of Science and Technology, Borg Al-Arab, Alexandria, Egypt.

Eng. Eltarabily published two papers as one of the authors before, they are "Studying the effect of core clay on seepage" and "Mathematical modeling for the effect of clay wall on seepage and sand box verification".

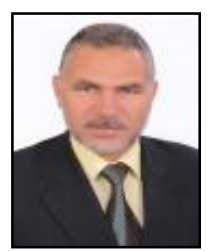

Abdelazim Negm was born in Sharkia, Egypt on April 16, 1962. He graduated in May 1985 from Zagazig University, Zagazig, Egypt. He was awarded the B.Sc. degree in irrigation and environmental engineering. Negm has also been awarded the master degree of science in civil engineering (irrigation and hydraulics) from Ain Shams University, Egypt and the PhD degree in hydraulics in 1992 from Zagazig University.

Currently, he is a professor of water resources in Egypt-Japan University for Science and Technology (E-JUST) and the chairman of the Environmental Engineering Dept. at E-JUST. He worked as a demonstrator in the Faculty of Engineering, Zagazig University in 1986 and continued till he occupied the position of vice dean of Academic and Student Affair. He published about 220 papers in national and international journals and conferences. He is listed in (a) Marquis Who is Who?, (b) IBC's 2000 Outstanding Intellectuals of the 21st Century , and (c) ABI directory for his achievement in the field of hydraulics and water resources. He has awarded the prizes of best papers three times. His research areas include hydraulic, hydrology and water resources. Currently, he is very interested in the sustainability and green environment.

Prof. Negm is a member of IAHR and a member of the Egyptian Permanent Promotion Committee for professorship promotion in field of water resources. He is also a member of the editorial board of several scientific journals and a member of the organizing committee of IWTC18 and he is the secretary general of the conference as well. 